\title{
Effect of Surface Deposited Rare Earth Oxide Gel Characteristics on Cyclic Oxidation Behavior of Fe20-Cr Alloys
}

\author{
Stela Maria Cristina Fernandes, Lalgudi Venkataraman Ramanathan* \\ Instituto de Pesquisas Energéticas e Nucleares - IPEN, \\ Av. Prof. Lineu Prestes, 2242, Cidade Universitária, 05508-000 São Paulo - Brazil
}

Received: July 13, 2005; Revised: December 29, 2005

\begin{abstract}
Rare earths have been used to increase high temperature oxidation resistance of many chromium dioxide and alumina forming alloys. These rare earths can be added as elements (or as oxide dispersions) to the alloys or applied as an oxide coating to the alloy surface. The sol-gel technique is considered to be very efficient to apply fine oxide particle coatings. Oxide gel coatings of various rare earths such as lanthanum, cerium, praseodymium, neodymium, samarium, gadolinium, dysprosium, yttrium, erbium and ytterbium have been applied to an iron-chromium alloy to determine their influence on the cyclic oxidation behavior (RT-900 ${ }^{\circ} \mathrm{C}$ ) of the alloy. The morphology and coverage of the rare earth oxide gels varied with the type of rare earth. The cyclic oxidation resistance of the alloy increased with increase in time at temperature required to reach a specific chromium dioxide layer thickness and this in turn was influenced by the rare earth ion radius and characteristics of the rare earth oxide coating such as morphology, stability, coverage, resistance to thermal stresses and consequently adhesion.
\end{abstract}

Keywords: rare earth oxide, sol-gel, coating, iron-chromium alloy, high temperature cyclic oxidation, chromium dioxide, morphology, coverage, ion radius, protection, oxide spalling

\section{Introduction}

Reactive elements such as the rare earths (REs) have been added to chromium dioxide and alumina forming alloys to improve oxidation resistance. The improvements are in the form of reduced oxidation rates and increased scale adhesion ${ }^{1,2}$. The REs can be added in elemental form or as oxide dispersions. It can also be applied as an oxide coating to the surface of the alloy ${ }^{2-4}$. Application of RE oxides to metallic surfaces can be achieved by immersion in aqueous RE nitrate solutions followed by thermal decomposition of the solid nitrate to oxide. Other precursors for RE oxide coatings can be molten nitrate salts, oxide slurries, or colloidal dispersions of a hydrous oxide (sol). The sol gel technique has been shown to generate the smallest oxide particles $^{5}$. This technique has been used to produce a range of oxide coatings. Essentially, it is based on the use of sols, which consists of a stable dispersion in a liquid of colloidal units of hydrous oxides or hydroxides ranging in size between $2 \mathrm{~nm}$ to $1 \mu \mathrm{m}$. The sol is applied to a metallic substrate by a suitable technique, such as dipping, spin coating or electrophoresis. On drying, (removing water from the colloidal units) the sol is transformed to a gel ${ }^{5}$.

The use of RE oxide coatings has the advantage of not affecting adversely the mechanical properties of the alloy and has also the potential of being used on surfaces of metallic components in service and exposed to high temperature oxidizing environments. In a study of the influence of praseodymium, dysprosium and yttrium oxide gel coatings on isothermal oxidation behavior of $\mathrm{Fe} 20-\mathrm{Cr}$ alloys, the morphology of the RE oxide gel was reported to vary with the type of $\mathrm{RE}^{6}$. A direct correlation between the RE ion radius and the extent of influence on chromium dioxide growth rate was also reported ${ }^{6}$.

This paper presents the influence of oxide coatings of cerium, dysprosium, erbium, gadolinium, lanthanum, neodymium, praseodymium, samarium, ytterbium and yttrium on the cyclic oxidation behavior of $\mathrm{Fe} 20-\mathrm{Cr}$ alloys. The effect of rare earth ion radius and the RE oxide coating characteristics such as morphology and coverage on chromium dioxide growth and consequently the cyclic oxidation resistance of the alloy has been studied.

\section{Methods and Materials}

Sols of $\mathrm{La}_{2} \mathrm{O}_{3}, \mathrm{CeO}_{2}, \mathrm{Pr}_{2} \mathrm{O}_{3}, \mathrm{Nd}_{2} \mathrm{O}_{3}, \mathrm{Sm}_{2} \mathrm{O}_{3}, \mathrm{Gd}_{2} \mathrm{O}_{3}, \mathrm{Dy}_{2} \mathrm{O}_{3}$, $\mathrm{Y}_{2} \mathrm{O}_{3}, \mathrm{Er}_{2} \mathrm{O}_{3}$, and $\mathrm{Yb}_{2} \mathrm{O}_{3}$, were prepared as aqueous dispersions of the respective rare earth oxides with nitric acid, and a non-ionic surfactant. The solution was heated to $80^{\circ} \mathrm{C}$ under constant agitation for an hour and the sol formed as sediment. Fe-20Cr alloy specimens $1.0 \times 1.0 \times 0.5 \mathrm{~cm}$ were ground to $400 \mathrm{mesh}$, rinsed and dried. The $\mathrm{RE}$ oxide sol was sprayed on the specimen to form a coat. The specimens were then heated to $150{ }^{\circ} \mathrm{C}$ to form a $10 \mu \mathrm{m}$ thick surface layer of RE oxide gel. The specimens were oxidized for 2 hours at $900{ }^{\circ} \mathrm{C}$ and cooled to room temperature. This consisted of one oxidation cycle. The specimens were weighed after each cycle and further oxidation of the specimens was discontinued when oxide spalling was observed. The surfaces of the specimens were examined before, between oxidation cycles and after the last oxidation cycle in an optical microscope coupled to an image analysis system and in a scanning electron microscope coupled to an energy dispersive spectroscopic system.

\section{Results and Discussion}

The cyclic oxidation behavior of uncoated and RE oxide coated $\mathrm{Fe}-20 \mathrm{Cr}$ alloy specimens is shown in Figure 1. The weight gain during oxidation is due to formation of $\mathrm{Cr}_{2} \mathrm{O}_{3}$ on the specimen surfaces ${ }^{6}$. The uncoated specimen was cycled five times before surface oxide spalling occurred. The RE oxide coated specimens were cycled many more times, indicating increased cyclic oxidation resistance and this varied with the RE oxide. Table 1 presents specimen weight gains after one cycle and when spalling commenced, along with the of cycles of 
oxidation before spalling. The table also lists the ratio of the radius of the $\mathrm{RE}$ ion to the radius of the chromium ion $\left(\mathrm{R}_{\mathrm{RE}} / \mathrm{R}_{\mathrm{Cr}}\right)$. It is evident that specimens coated with $\mathrm{RE}$ oxides that have $\mathrm{R}_{\mathrm{RE}} / \mathrm{R}_{\mathrm{Cr}}$ ratios lower than 1.45 withstood only half as many cycles as those coated with $\mathrm{RE}$ oxides that had $\mathrm{R}_{\mathrm{RE}} / \mathrm{R}_{\mathrm{Cr}}$ ratios higher than 1.45.

The weight gains of the oxide coated specimens after one cycle of oxidation and when spalling commenced varied quite significantly. The chromia layer on specimens coated with La and Pr oxides did not spall even after 15 cycles. The weight gains of these specimens after one cycle and after 15 cycles were low and about $0.17 \mathrm{mg} . \mathrm{cm}^{-2}$. After one cycle of oxidation the weight gain of the $\mathrm{La}_{2} \mathrm{O}_{3}$ coated specimen was one quarter that of the specimen coated with $\mathrm{Yb}_{2} \mathrm{O}_{3}$. A significant part of the weight gain of specimens coated with $\mathrm{La}_{2} \mathrm{O}_{3}$ and $\operatorname{Pr}_{2} \mathrm{O}_{3}$, due to chromium dioxide growth, occurred during the first cycle of oxidation. In general, spalling of chromium dioxide layer

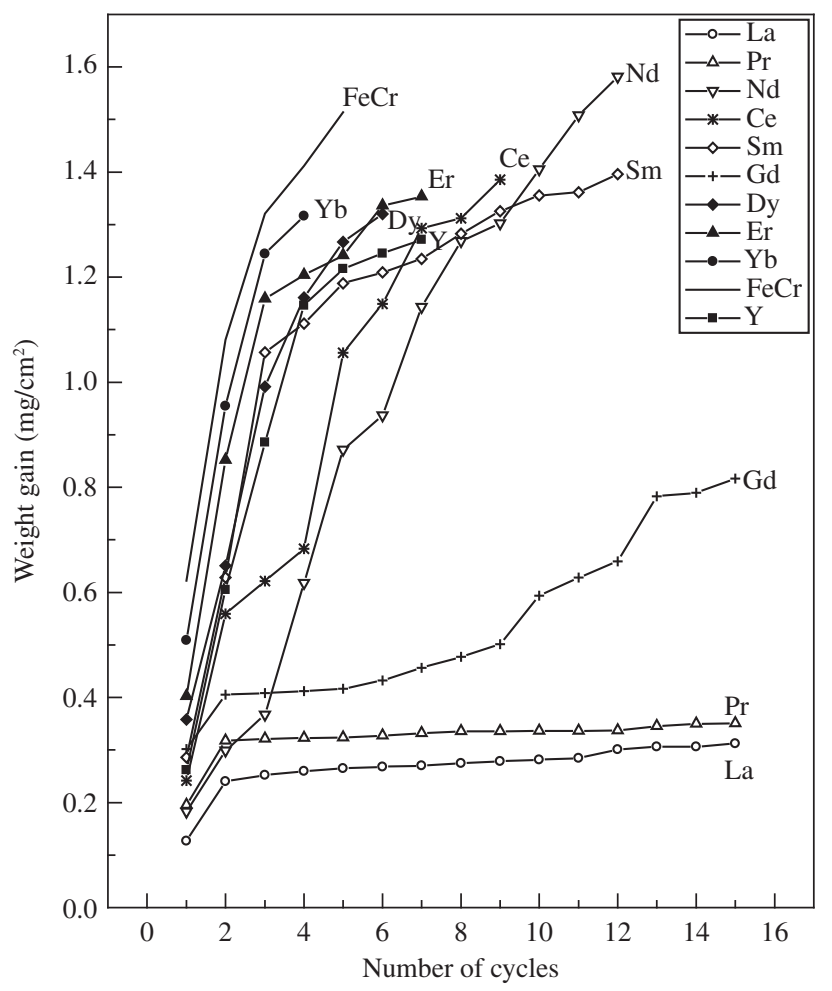

Figure 1. Weight gain vs. number of cycles of oxidation of $\mathrm{Fe}-20 \mathrm{Cr}$ alloy without and with surface deposited RE oxide. occurred when weight gains were above a certain value, in the range $1.25-1.5 \mathrm{mg} . \mathrm{cm}^{-2}$. It can be seen that the chromium dioxide layer on specimens coated with $\mathrm{Dy}_{2} \mathrm{O}_{3}, \mathrm{Y}_{2} \mathrm{O}_{3}, \mathrm{Er}_{2} \mathrm{O}_{3}$ and $\mathrm{Yb}_{2} \mathrm{O}_{3}$ spalled when weight gains reached about $1.3 \mathrm{mg} . \mathrm{cm}^{-2}$. Specimens coated with $\mathrm{Nd}_{2} \mathrm{O}_{3}$ and $\mathrm{Sm}_{2} \mathrm{O}_{3}$ withstood many more cycles of oxidation in spite of significant weight gains. This is contrary to expectations where in specimens that withstand a higher number of cycles of oxidation, have relatively lower weight gains. These observations suggest that increase in cyclic oxidation resistance of RE oxide coated $\mathrm{Fe} 20-\mathrm{Cr}$ alloy is not just dependent on the ionic radius of the rare earth in the coating.

Scanning electron micrographs of the different RE oxide gels are shown in Figure 2. Marked differences in the morphology of the oxides can be seen. Similar observations, with respect to morphological variations, have been reported by other authors ${ }^{3}$. Table 2 summarizes the morphological characteristics of the oxides. Comparison of data in Tables 2 and 1 indicates a correlation between the morphology of the RE oxide and the cyclic oxidation resistance of the specimen coated with that RE oxide. Specimens coated RE oxides with cube, rod or needle-like morphology withstood a higher number of oxidation cycles compared to those coated with RE oxides with platelet or cluster morphology. In the optical microscopic examinations of coated specimen surfaces, coverage, or the extent to which the surface was covered, was evaluated using the image analyzer.

Figures $3 \mathrm{a}$ and $3 \mathrm{~b}$ show the micrographs of the alloy surface covered with $\mathrm{La}_{2} \mathrm{O}_{3}$ and $\mathrm{Yb}_{2} \mathrm{O}_{3}$. The area fractions, or coverage, of these two oxides and the other oxides were determined from image analysis measurements. The coverage of the different RE oxide is summarized in Table 3. The cyclic oxidation resistance of the alloy

Table 2. Main morphological feature of the rare earth oxides.

\begin{tabular}{ll}
\hline Rare earth oxide & Main morphological feature \\
\hline Lanthanum & Cubes and rods \\
Cerium & Cubes \\
Praseodymium & Cuboids \\
Neodymium & Fine needles, acicular \\
Samarium & Clusters \\
Gadolinium & Interlocking clusters \\
Dysprosium & Tiny clusters \\
Yttrium & Platelets \\
Erbium & Open clusters \\
Ytterbium & Clusters and disperse platelets \\
\hline
\end{tabular}

Table 1. Weight gains of the RE oxide coated $\mathrm{Fe} 20-\mathrm{Cr}$ specimens, number of oxidation cycles withstood before spalling and the ratios of the RE ion radius to the radius of chromium ion.

\begin{tabular}{|c|c|c|c|c|c|}
\hline Oxide of & $\begin{array}{c}\text { Weight gain after } \\
1 \text { cycle } \mathrm{W}_{1}\left(\mathrm{mg} \mathrm{cm}^{-2}\right)\end{array}$ & $\begin{array}{l}\text { Weight gain at spall } \\
\mathrm{W}_{\mathrm{s}}\left(\mathrm{mg} \cdot \mathrm{cm}^{-2}\right)\end{array}$ & $\begin{array}{c}\Delta \mathrm{w}\left(\mathrm{W}_{\mathrm{s}}-\mathrm{W}_{1}\right) \\
\left(\mathrm{mg} \cdot \mathrm{cm}^{-2}\right)\end{array}$ & $\begin{array}{c}\text { Number of cycles } \\
\text { at spall }\end{array}$ & $\mathrm{R}_{\mathrm{RE}} / \mathrm{R}_{\mathrm{Cr}}$ ratio \\
\hline Lanthanum & 0.125 & 0.30 & 0.175 & $15+$ & 1.64 \\
\hline Cerium & 0.230 & 1.40 & 1.170 & 9 & 1.60 \\
\hline Praseodymium & 0.190 & 0.35 & 0.160 & $15+$ & 1.57 \\
\hline Neodymium & 0.180 & 1.58 & 1.400 & 12 & 1.54 \\
\hline Samarium & 0.280 & 1.40 & 1.120 & 12 & 1.50 \\
\hline Gadolinium & 0.300 & 0.90 & 0.600 & $15+$ & 1.46 \\
\hline Dysprosium & 0.350 & 1.30 & 0.950 & 6 & 1.42 \\
\hline Yttrium & 0.250 & 1.25 & 1.000 & 7 & 1.39 \\
\hline Erbium & 0.400 & 1.35 & 0.950 & 7 & 1.37 \\
\hline Ytterbium & 0.500 & 1.31 & 0.810 & 4 & 1.34 \\
\hline
\end{tabular}



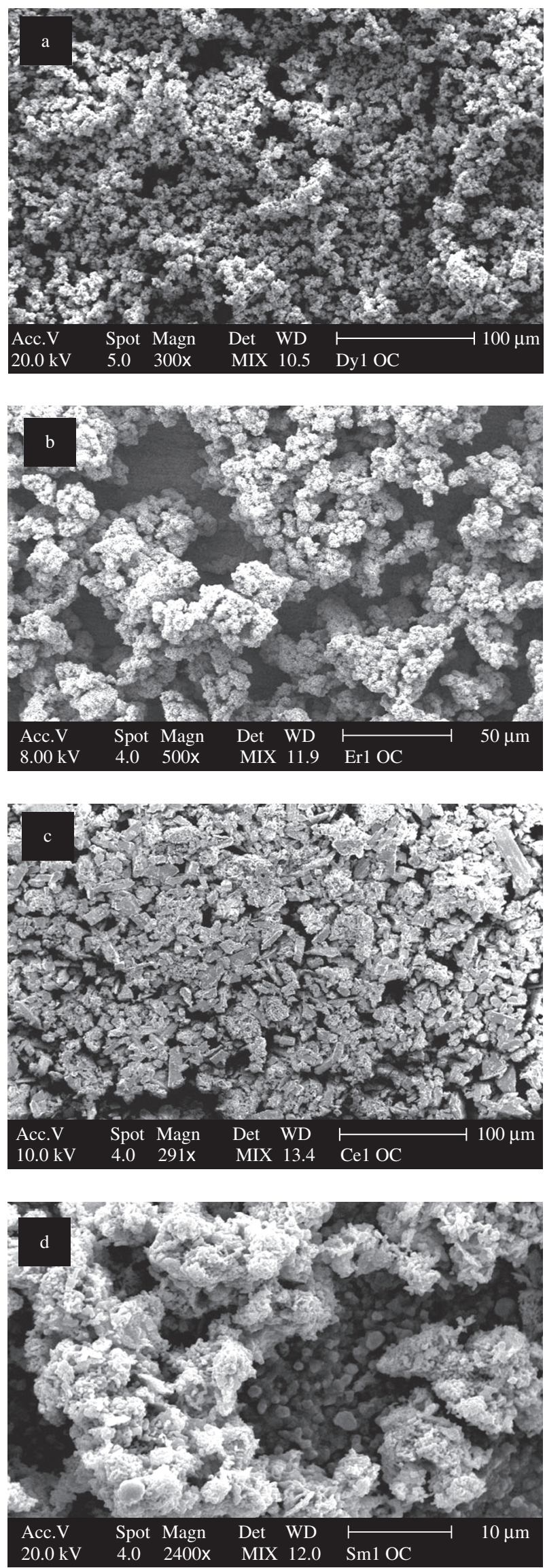
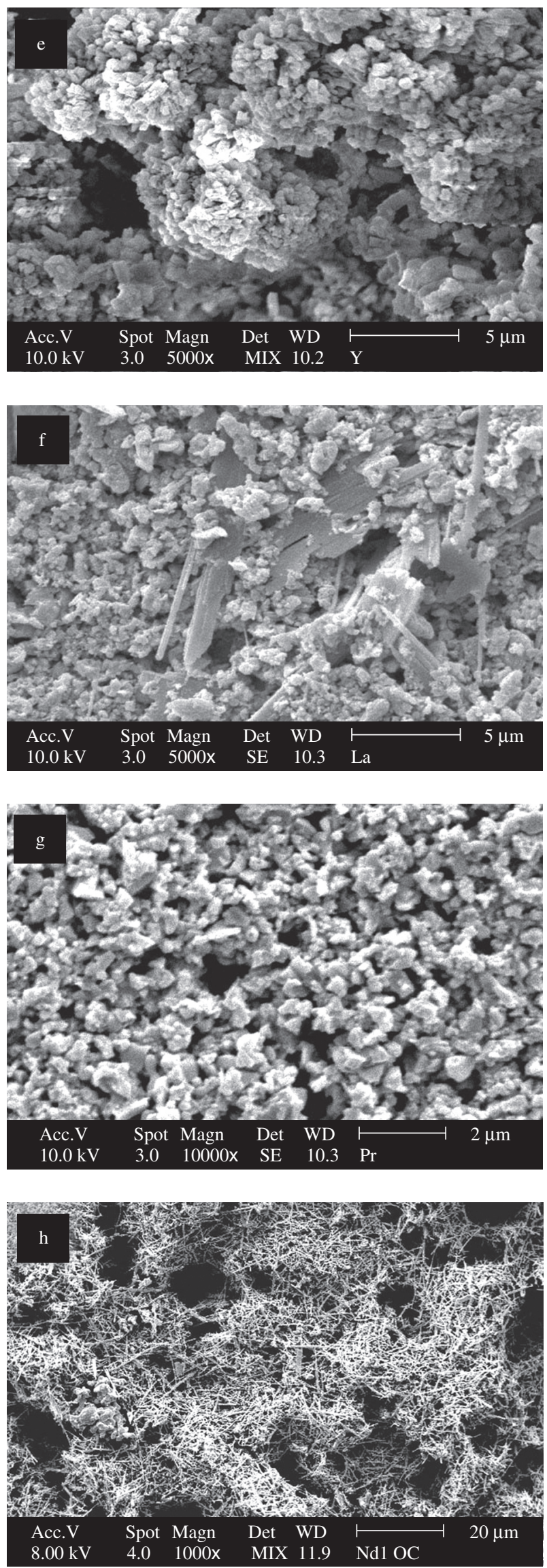

Figure 2. Scanning electron micrographs of different RE oxides. a) Dy; b) Er; c) Ce; d) Sm; e) Y; f) La; g) Pr; h) Nd; i) Gd; and j) Yb. Continued next page.. 

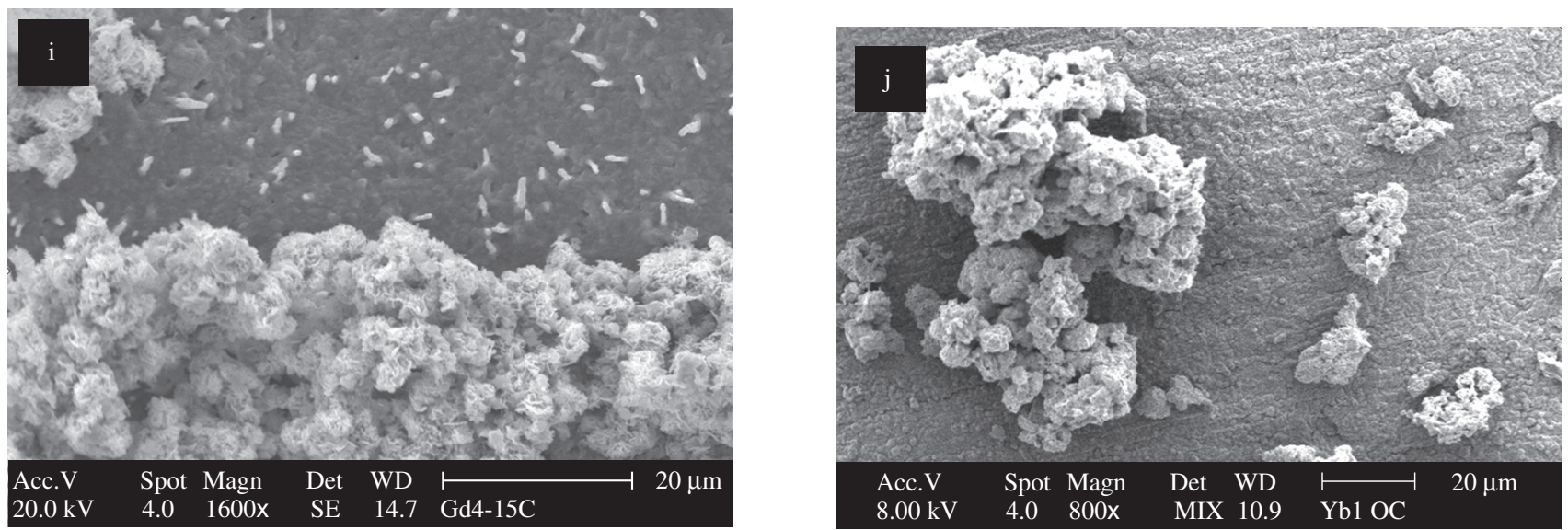

Figure 2. Scanning electron micrographs of different RE oxides. a) Dy; b) Er; c) Ce; d) Sm; e) Y; f) La; g) Pr; h) Nd; i) Gd; and j) Yb.
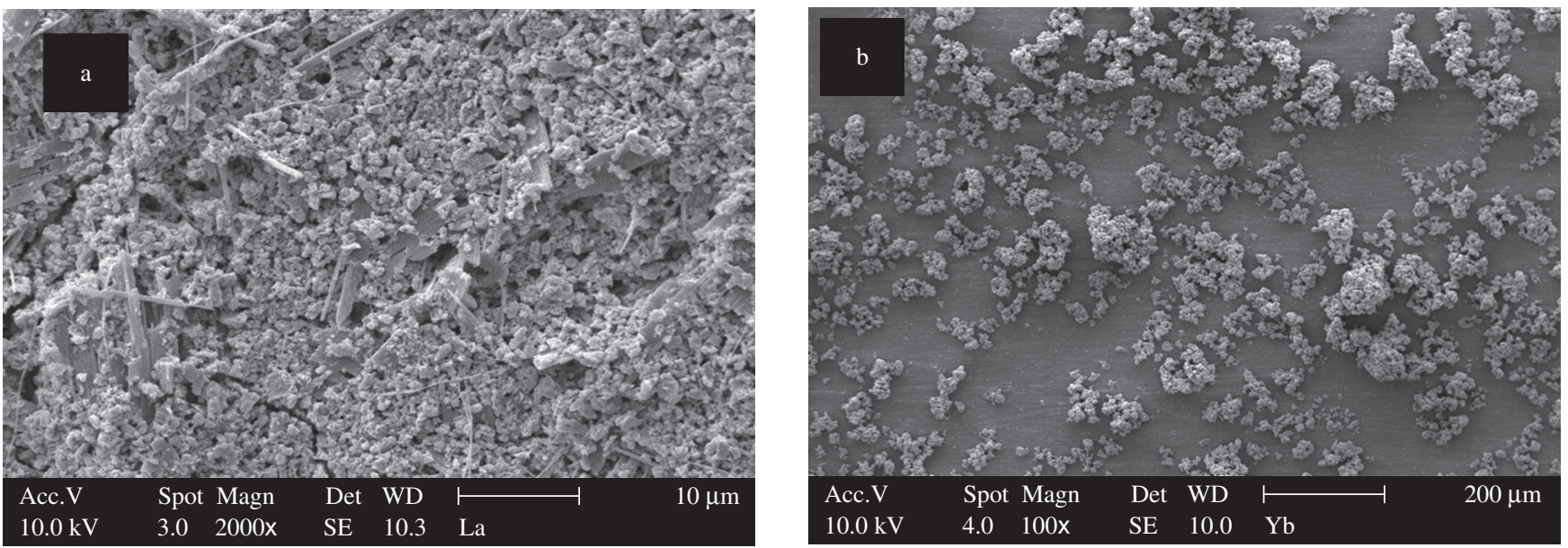

Figure 3. Alloy surface coated with: a) $\mathrm{La}_{2} \mathrm{O}_{3}$; and b) $\mathrm{Yb}_{2} \mathrm{O}_{3}$.

Table 3. Correlation between coverage of RE oxide coat and cyclic oxidation resistance.

\begin{tabular}{lcccc}
\hline Rare earth element & $\begin{array}{c}\text { Magnification in } \\
\text { micrograph (microns) }\end{array}$ & $\begin{array}{c}\text { Bit plane \% of covered } \\
\text { surface }\end{array}$ & $\begin{array}{c}\text { Ranking of RE oxide } \\
\text { coverage }\end{array}$ & Number of cycles \\
\hline Lanthanum & 2000 & 77.04 & 1 & 15 \\
Cerium & 200 & 68.60 & 6 & 9 \\
Praseodymium & 2500 & 72.03 & 2 & 15 \\
Neodymium & 200 & 97.12 & 3 & 12 \\
Samarium & 200 & 73.80 & 4 & 15 \\
Gadolinium & 125 & 71.30 & 8 & 6 \\
Dysprosium & 200 & 72.00 & 5 & 7 \\
Yttrium & 250 & 68.10 & 7 & 7 \\
Erbium & 100 & 55.20 & 9 & 10 \\
Ytterbium & 100 & 22.80 & & 4 \\
\hline
\end{tabular}

coated with the different RE oxides is also shown in Table 3, to help correlate the two parameters. This table clearly indicates a correspondence between the extent of coverage and the cyclic oxidation resistance. The exceptions are cerium and gadolinium oxides. The influence of the former can be attributed to its valence. Cerium oxide has the formula $\mathrm{CeO}_{2}$ where as the other RE oxides have the general formula $\mathrm{RE}_{2} \mathrm{O}_{3}$.

The morphology of the RE oxide coating before and after oxidation at $1000{ }^{\circ} \mathrm{C}$ were compared and found to remain unchanged. This lent further proof to the fact that the RE oxide particle shape and size are defined during the sol (dispersion) to gel (solid) conversion stage and are maintained during subsequent oxidation.

The data presented indicate that the cyclic oxidation resistance of Fe20-Cr alloy depends on the thickness of the chromium dioxide layer formed on the alloy surface. In the presence of an RE oxide coating the chromium dioxide layer formed after the first cycle of oxidation is thinner than that on surfaces without a RE oxide coating and it varies in thickness, depending on the RE oxide. Spalling of the chromium 
dioxide layer, which marks the breakdown of cyclic oxidation resistance, occurs when its thickness reaches a critical value. Hence, the longer it takes for the chromium dioxide to reach this thickness, higher the cyclic oxidation resistance. Characteristics of the RE oxide coating that affect the time required for the chromium dioxide layer thickness to reach the critical value include the ionic radii of the RE, the shape and size of the RE oxide crystallites and the coverage.

\section{General Discussion}

Growth of chromium dioxide on $\mathrm{RE}$ free $\mathrm{Fe}-\mathrm{Cr}$ alloys is cation driven, and the oxide scale growth takes place at the oxide/oxygen interface, due mainly to the higher mobility of $\mathrm{Cr}$ ions compared to the oxygen ions ${ }^{7,8}$. The reduced chromium dioxide growth rate in the presence of REs is directly linked to reduction in chromium ion mobility. Since grain boundaries are the preferred paths for ion transport in compact scales, the reduced chromium dioxide growth rate in the presence of REs is due to reduction in chromium ion movement along grain boundaries, caused by the presence of barriers. These barriers are the RE ions. Proof of this was reported earlier ${ }^{6}$. Similar observations were presented by Papaiacovou e Hussey. for scale growth on ceria coated $\mathrm{Fe}-\mathrm{Cr}$ alloys 9 .

The thickness of the chromium dioxide layer formed during the first cycle of oxidation varies, depending on the RE oxide. The chromium dioxide layer formed during the first cycle in the presence of $\mathrm{La}_{2} \mathrm{O}_{3}$ and $\operatorname{Pr}_{2} \mathrm{O}_{3}$ is significantly thinner than that formed in the presence of the other RE oxides. A thin layer of chromium dioxide withstands better the stresses associated with scale growth and temperature cycling, and is therefore more adherent to the alloy.

In cyclic oxidation, the $\mathrm{Cr}_{2} \mathrm{O}_{3}$ layer formed during the first cycle is influenced by the RE, in the same manner as in isothermal oxidation. The RE ions are significantly larger than $\mathrm{Fe}$ or $\mathrm{Cr}$ ions, and their ionic radii are 1.3 to 1.65 times that of $\mathrm{Cr}$. The extents to which $\mathrm{RE}$ elements affect oxidation rates have been found to be proportional to their sizes ${ }^{6}$. The larger the RE ion, greater its influence. It is therefore possible that fewer RE ions are needed at the oxide grain boundaries to block chromium ion movement. Further proof of a direct correlation between RE ion radius and cyclic oxidation resistance has been found. This also supports the mechanism by which REs influence chromium dioxide scale growth, that is, the presence of RE ions at the oxide grain boundaries effectively blocks $\mathrm{Cr}$ ion movement and makes thereby, anion (oxygen ion) movement predominant. The thickness of the $\mathrm{Cr}_{2} \mathrm{O}_{3}$ layer that forms varies with the $\mathrm{RE}$ in the coating. The $\mathrm{Cr}_{2} \mathrm{O}_{3}$ and the RE oxide coat remain adherent during the first few cycles. The increase in $\mathrm{Cr}_{2} \mathrm{O}_{3}$ layer thickness and RE oxide coating loss happens simultaneously. The extent to which the RE oxide coating is lost depends on its morphology. The morphology of the RE oxide determines the coverage and adhesion of the RE oxide.

The time required for the chromium dioxide layer to reach the critical thickness, and thereby the cyclic oxidation resistance depends on characteristics of the RE oxides which in decreasing order of influence are: RE ion radius, RE oxide morphology, RE oxide coverage and adhesion or resistance to thermal or scale growth stresses. Coverage has been observed to depend on morphology and the latter influences adhesion.

\section{Conclusions}

1. The cyclic oxidation resistance of RE oxide coated $\mathrm{Fe}-20 \mathrm{Cr}$ alloy was significantly higher than that of the uncoated alloy;

2. The RE oxides in decreasing order of influence on cyclic oxidation resistance of Fe20-Cr alloy are: $\mathrm{La}_{2} \mathrm{O}_{3}, \mathrm{Pr}_{2} \mathrm{O}_{3}, \mathrm{Gd}_{2} \mathrm{O}_{3}$, $\mathrm{Sm}_{2} \mathrm{O}_{3}, \mathrm{Nd}_{2} \mathrm{O}_{3}, \mathrm{CeO}_{2}, \mathrm{Y}_{2} \mathrm{O}_{3}, \mathrm{Er}_{2} \mathrm{O}_{3}, \mathrm{Dy}_{2} \mathrm{O}_{3}$, and $\mathrm{Yb}_{2} \mathrm{O}_{3}$;

3. The morphology and coverage of the RE oxide coating on the $\mathrm{Fe}-20 \mathrm{Cr}$ alloy surface varied with the RE and influenced cyclic oxidation resistance;

4. Further proof of a direct correlation between RE ion radius and cyclic oxidation resistance of $\mathrm{Fe} 20-\mathrm{Cr}$ alloy has been observed; and

5. The influence of RE oxide characteristics on cyclic oxidation resistance of $\mathrm{Fe} 20-\mathrm{Cr}$ alloy, in decreasing order of influence are: $\mathrm{RE}$ ion radius, $\mathrm{RE}$ oxide morphology, $\mathrm{RE}$ oxide stability at high temperature, coverage, resistance to thermal stresses and adhesion.

\section{References}

1. Stott FH. Influence of alloy additions on oxidation. Materials Science and Technology. 1989; 5:734-740.

2. Stringer J. The reactive elements effect in high temperature corrosion. Materials Science and Engineering. 1989; A120:129-137.

3. Hou PY, Stringer J. The effect of surface applied reactive metal oxide on the high temperature oxidation of alloys. Materials Science and Engineering. 1987; 87:295-302.

4. Ramanathan L. Role of rare earth elements on high temperature oxidation behavior of $\mathrm{Fe}-\mathrm{Cr}, \mathrm{Ni}-\mathrm{Cr}$ and $\mathrm{Ni}-\mathrm{Cr}-\mathrm{Al}$ alloys. Corrosion Science. 1993; 35(5-8):871-878

5. Bennett MJ. New coatings for high temperature materials protection. Journal of Vacuum Science and Technology. 1984; B2(4):800-805.

6. Fernandes SMC. Ramanathan LV, Influence of rare earth oxide coatings on oxidation behavior of Fé-20Cr alloys. Surface Engineering. 2000; 16(4):327-332.

7. Nagai H. Effect of rare earth metal and oxide additions on the high temperature oxidation of $\mathrm{Ni}-\mathrm{Cr}$ and $\mathrm{Fe}-\mathrm{Cr}$ alloys. Materials Science Forum. 1989; 43:75-130.

8. Moon DP. Role of reactive elements in alloy protection. Materials Science and Technology. 1989; 5:754-764.

9. Papaiacovou P, Hussey RJ. The effect of $\mathrm{CeO}_{2}$ coatings on the oxidation behavior of Fe-20Cr alloys in $\mathrm{O}_{2}$ at 1173K. Corrosion Science, 1990; 30(4/5):451-460 
